\title{
A New Kind of Water Resources Evaluation Standard
}

\author{
Chaowei Wang \\ School of Chaowei Wang,North China Electric Power University,Baoding 071000,China \\ 1009353563@qq.com,
}

Keywords: L-WSCI, water resource, water scarcity.

\begin{abstract}
First,I begin by establishing the L-WSCI model that takes the factors that affect both supply and demand. These are population growth rate, water availability, domestic, industrial and ecological water usage. This model is developed from the traditional WSCI model. The model's testing results, whose parameters are determined using data from China Statistical Yearbook, match perfectly with the water scarcity map, suggesting the validity of our improved model.Second, Tianjing is chosen in further investigation, where I invoke the L-WSCI model to assess the water resource situation. Based on the data like population, industrial water demand and other parameters in the L-WSCI model, concluding that physical scarcity is the primary cause for water scarcity, rather than economic scarcity.Third, using Grey Forecasting Model to get all the parameters in the L-WSCI model, and then these components are substituted to the L-WSCI model, so I obtain the relatively accurate water situation in 15 years for the chosen region. The results show that in pace with increasing of the value of the L-WSCI model, the water situation of Tianjingin 15 years become worse. And I find the physical scarcity is still the primary cause for water scarcity. For the citizens in Tianjing, they get the smaller annual per capita domestic demand than that in 2012.
\end{abstract}

\section{Introduction}

Water. It's an emotional word for people in all areas of the world. But one in three people already lives in a country with moderate to high water stress, and by 2030 nearly half the global population could be facing water scarcity, with demand outstripping supply by 40 per cent. When it comes to China, the country uses 600 billion cubic meters of water a year, or about 400 cubic meters a person,one quarter of what the average American uses and less than half the international definition of water stress. That is what we called the physical scarcity. On the other hand, economic scarcity is was also an important reason for this phenomenon. And the answer would be to improve the efficiency with which water is used. Only about $40 \%$ of water used in agriculture and industry is recycled, half as much as in Europe. The rest is dumped in rivers and lakes. In the same time, China is neglecting its urban water infrastructure, (for example, desalinization plants, water harvesting techniques or undiscovered aquifers), leading to more waste.

\section{Symbols and Definitions}

Table1

\begin{tabular}{|ccc|}
\hline SYMBOL & DEFINITION & UNITS \\
\hline $\mathbf{a}$ & Annual Freshwater Availability & billion cubic meters \\
\hline $\boldsymbol{\varepsilon}$ & $\begin{array}{c}\text { Annual Per Capita Domestic } \\
\text { Demand }\end{array}$ & billion cubic meters \\
\hline $\mathbf{Y}$ & $\begin{array}{c}\text { Annual Per Capita } \\
\text { Demand For Green Areas }\end{array}$ & billion cubic meters \\
\hline $\mathbf{\delta}$ & Irrigation Water Demands & billion cubic meters \\
\hline $\boldsymbol{A}$ & Population Growth Rate & Unitless \\
$\mathbf{\beta}$ & Population & ten thousand \\
\hline $\mathbf{t}$ & Time & year \\
\hline
\end{tabular}




\begin{tabular}{|ccc|}
\hline h & Annual Evapotranspiration & billion cubic meters \\
\hline b & $\begin{array}{c}\text { Environmental Water } \\
\text { Requirements }\end{array}$ & billion cubic meters \\
\hline $\mathbf{K}$ & Estimated Freshwater Losses & billion cubic meters \\
\hline $\mathbf{p}$ & Industrial Water Demand & billion cubic meters \\
\hline
\end{tabular}

\section{The Wsci Model}

The Wsci Model can measure the water availability of an area, which is described by the following ordinary equation.

$$
W_{s c i}=\left(\frac{\alpha}{\left(\frac{100}{100-p}\right) \beta e^{\lambda t}(\varepsilon+\gamma+\delta)\left(\frac{100}{100-\kappa}\right)+h+b}\right)-1
$$

The symbols are as defined in Table 1 . Compared to the other models, The Wsci Model takes annual evapotranspiration (h) and environmental water requirements (b) into account, which also have a significant impact on results. All of parameters needed could be found directly or indirectly on the website of the ministry of water resources of the Peoples Republic of China. For the parameter h, it could be described by the following equation.

\section{Improved Water Scarcity Model}

The L-Wsci Model could be described by improvedequation.

$$
W_{s c i}=\left(\frac{4000 * \alpha}{\left(\frac{100}{100-p}\right) \beta e^{\lambda t}(\varepsilon+\gamma+\delta)\left(\frac{100}{100-\kappa}\right)+h+b}\right)
$$

Then I still use the same data to check the Improved Model, The results are shown in Table2.

Table2:Modified Data

\begin{tabular}{cccccc}
\hline Hainan & Anhui & Hunan & Yunnan & Kweichow & Honan \\
0.53 & 4.84 & 4.93 & 7.27 & 18.30 & 27.52 \\
Shangtung & Kansu & Chungking & $\begin{array}{c}\text { Inner } \\
\text { Mongolia }\end{array}$ & Tianjing & \\
30.64 & 42.14 & 66.40 & 146.90 & 360.34 & \\
\hline
\end{tabular}

We can see from the Table 2, our results could assess the water resources situation directly and obviously without the disadvantages we refer to before.

In order to make the result more obvious based on the value of the L-Wsci Model and the real water resource situation we found on the website of the ministry of water resources of the Peoples Republic of China. The water conditions in an area can be categorized as: no stress, stress, scarcity, and absolute scarcity (Table3).

\begin{tabular}{cc} 
& Table3:Classification \\
\hline $\mathrm{L}-$ Wsci & Condition \\
\hline$<10$ & No Stress \\
\hline $10-20$ & Stress \\
$20-40$ & Scarcity \\
$>40$ & Absolute Scarcity \\
\hline
\end{tabular}

From the Table3, we can find that in most areas, namely, Inner Mongolia, Tianjing and Kansu, (Figure 2)the model fits well to the real data of UN water scarcity map. However, our model also regards Chungking as a region deficient of water, which is contrary information with UN water scarcity map .Through analysis, it is data that lead to difference between results of simulation and the data given. The original data in the UN water scarcity map is from a paper written in 2004.From 2004 to the time we study -2012, the population in Chungking soared from 28 million to 30 million. And the Chinese government identifies Chungking as a province that is short for water due to the 
demographic reasons. Then we looked up the data in 2012, all of 4 provinces which the Improved Water Scarcity Model identifies as a region deficient of water are also identifies as provinces lack of water by Chinese government.

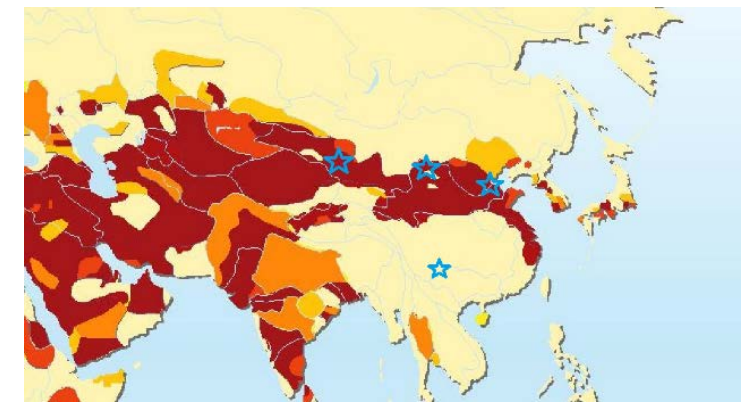

Figure 2:Thirsty Regions

In conclusion, The L-Wsci Model is an effective tool to assess the situation of water resources in different kinds of practical situation.

\section{Choose a Region}

I choose one of the absolute scarcity region_-Tianjing(Figure 3) as the study region.After Looking up detail water resources information about Tianjing and other regions, there are two parameters, specifically annual per capita domestic demand and the percentage of using for living water deserves attention.

Compared to other regions, like Anhui and Hunan which are No Stress regions, annual per capita domestic demand appears very small truly(table 4).

Table 4:Comparison in $\boldsymbol{\varepsilon}$

\begin{tabular}{cc}
\hline Region & $\begin{array}{c}\text { Annual Per Capita Domestic Demand } \\
(\varepsilon)\end{array}$ \\
\hline Hunan & 45.55 \\
\hline Anhui & 40.01 \\
\hline Tianjing & 25.42 \\
\hline
\end{tabular}

First, according to the data from Water Affairs Bureau of Tianjing, available clean water mainly originated from the atmospheric rainfall, which could become ground water and be used directly later. Usually $20 \%$ to $50 \%$ of atmospheric rainfall could turn into ground water, and this number would be $30 \%$ in city. Total precipitation is 10.1billion cubic meter in Tianjing in 2012.Then we could know that the available clean water is only 3 billion cubic meter in this region a year. So its maximal value for living water is 3 billion cubic meter and is hardly to meet the demand. These imply that inadequate water in physics could be a main cause for water scarcity.

Second, as for the management problem, we don't think Tianjing have this matter due to the following reasons. As we know from the former section, the maximal value for living water is 3 billion cubic meter in this region. But according to the data from Water Affairs Bureau of Tianjing, the water consumption was 2.3 billion cubic meter in same condition. It could easy to get the workpiece ratio is $76 \%$.

In summary, in terms of the object we study, physical scarcity is the primary cause for water scarcity.

\section{Forecast the water situation in 15 years}

In grey forecasting, we make a scientific quantitative prediction for the future condition of the system by raw data processing and grey model building.

We use all the parameters that we predicted above to calculate the index in The L-Wsci Model and the following table shows the results (table 5). 
Table 5: Predict Results

\begin{tabular}{cccccccc}
\hline $\mathbf{2 0 1 6}$ & $\mathbf{2 0 1 7}$ & $\mathbf{2 0 1 8}$ & $\mathbf{2 0 1 9}$ & $\mathbf{2 0 2 0}$ & $\mathbf{2 0 2 1}$ & $\mathbf{2 0 2 2}$ & $\mathbf{2 0 2 3}$ \\
\hline 265.1381 & 273.2053 & 280.4846 & 287.4083 & 296.7817 & 308.2645 & 320.262 & 332.0044 \\
\hline $\mathbf{2 0 2 4}$ & $\mathbf{2 0 2 5}$ & $\mathbf{2 0 2 6}$ & $\mathbf{2 0 2 7}$ & $\mathbf{2 0 2 8}$ & $\mathbf{2 0 2 9}$ & $\mathbf{2 0 3 0}$ & \\
\hline 314.3587 & 320.4672 & 327.5357 & 333.0701 & 339.4149 & 332.7683 & 339.2988 & \\
\hline
\end{tabular}

\section{Summary}

From the table above, in pace with increasing of the index above, the water situation of Tianjingin 15 years become worse. And I think the physical scarcity is still the primary cause for water scarcity. For the lives of citizens of this region, they get the smaller annual per capita domestic demand than that in 2012.

\section{References}

[1]Amber Brown;Marty D.Matlock,A Review of Water Scarcity Indices and Methodologies.White Paper \#106 | April 2011

[2] Xie N, Liu S. Discrete GM $(1,1)$ and Mechanism of Grey Forecasting Model [J][J]. Systems Engineering-theory \& Practice, 2005, 1: 014.

[3] Brown A, Matlock M D. A review of water scarcity indices and methodologies[J]. White paper, 2011, 106.

[4] China Statistical Yearbook http://www.stats.gov.cn/tjsj/ndsj/

[5] Integrated Query Service Platform http://www.mwr.gov.cn/zxfw/zhcxfwpt/dfsl/

[6] Tianjing Map https://en.wikipedia.org/wiki/Tianjin

[7]de Fraiture C. Assessment of potential of food supply anddemand using the Watersim model[J]. Columbo: International Water Management Institute, 2005.

[8]Gober P, Wentz E A, Lant T, et al. WaterSim: a simulation model for urban water planning in Ph oenix, Arizona,USA[J].Environment and Planning B: Planning and Design, 2011, 38(2):197-215.

[9]Gober P,Wentz E A,Lant T,et al.WaterSim:a simulation model for urban water planning in Phoe nix,Arizona,USA[J].Environment and Planning B: Planning and Design,2011,38(2):197-215.

[10]Viala E. Water for food, water for life a comprehensive assessment of water management in agr iculture[J]. Irrigation and Drainage Systems, 2008, 22(1): 127-129. 